\title{
Oat bran and wheat bran impact net energy by shaping microbial communities and fermentation products in pigs fed diets with or without xylanase
}

Zhiqian Lyu ${ }^{1,2}$, Li Wang ${ }^{1}$, Jinrong Wang ${ }^{3}$, Zhenyu Wang ${ }^{1}$, Shuai Zhang ${ }^{1}$, Junjun Wang ${ }^{1}$, Jinlong Cheng ${ }^{4}$ and Changhua Lai ${ }^{1 *}$ D

\begin{abstract}
Background: Dietary fiber can be fermented in gut of pigs and the end products of fermentation were short-chain fatty acids (SCFA). The SCFA had positive effects on gut bacteria and host immune system. In addition, SCFA can provide a part of available energy for pigs. However, there were limited reports on the relationship between dietary fiber, gut bacteria, and energy metabolism. Therefore, this study investigated how dietary fiber and enzyme addition impacted energy metabolism by acting on the microbial community and SCFA.

Methods: Wheat bran (WB) was added to the corn-soybean meal-based diet at the levels of $12 \%$ and $27 \%$, and oat bran (OB) at $15 \%$ and $36 \%$. One of each diet was supplemented with or without $5000 \mathrm{U} / \mathrm{kg}$ feed of xylanase, so a total of 10 diets were allotted to 60 growing pigs (initial body weight: $27.2 \pm 1.2 \mathrm{~kg}$ ) using a randomized complete block design. The experiment was conducted in 10 consecutive periods using 6 similar open-circuit respiration chambers. Each pig was used for one 20-day period. During each period, six pigs were allowed $14 \mathrm{~d}$ to adapt to the diets in metabolic cages followed by $6 \mathrm{~d}$ (from d 15 to $\mathrm{d} 20$ ) in respiration chambers to measure heat production (HP).
\end{abstract}

Results: Pigs fed 36\% OB diets had greater $(P<0.05)$ nutrient digestibility and net energy (NE) values compared to those fed 27\% WB diets. Apparent digestibility coefficients of dry matter (DM) and crude protein (CP) were lower $(P<0.05)$ in pigs fed 27\% WB diets compared with those fed 12\% WB diets. Enzyme addition improved $(P<0.05)$ the NE values (11.37 vs. $12.43 \mathrm{MJ} / \mathrm{kg} \mathrm{DM}$ ) in diets with $27 \% \mathrm{WB}$. Supplementation of xylanase did not affect NE values for basal diets, OB diets and 12\%WB diets. Compared with diets with 36\% OB, pigs fed 27\% WB-based diets excreted more total SCFA, acetate and propionate (expressed as $\mathrm{g} / \mathrm{kg}$ feed $\mathrm{DM}$ ) in fecal samples of pigs $(P<0.05)$. Pigs in the WB diets had greater proportion of phylum Bacteroidetes while phylum Firmicutes were greater in pigs fed OB diets $(P<0.05)$. Pigs fed WB diets had greater $(P<0.05)$ abundance of Succinivibrio and Prevotella, which were associated with fiber degradation and SCFA production.

(Continued on next page)

\footnotetext{
*Correspondence: laichanghua999@163.com

'State Key Laboratory of Animal Nutrition, College of Animal Science and Technology, China Agricultural University, No. 2 Yuanmingyuan West Road, Beijing 100193, China

Full list of author information is available at the end of the article
}

(c) The Author(s). 2020 Open Access This article is licensed under a Creative Commons Attribution 4.0 International License, which permits use, sharing, adaptation, distribution and reproduction in any medium or format, as long as you give appropriate credit to the original author(s) and the source, provide a link to the Creative Commons licence, and indicate if changes were made. The images or other third party material in this article are included in the article's Creative Commons licence, unless indicated otherwise in a credit line to the material. If material is not included in the article's Creative Commons licence and your intended use is not permitted by statutory regulation or exceeds the permitted use, you will need to obtain permission directly from the copyright holder. To view a copy of this licence, visit http://creativecommons.org/licenses/by/4.0/. The Creative Commons Public Domain Dedication waiver (http://creativecommons.org/publicdomain/zero/1.0/) applies to the data made available in this article, unless otherwise stated in a credit line to the data. 


\begin{abstract}
(Continued from previous page)
Conclusion: Our results indicated diets supplied by high level of OB or WB promote the growth of fiber-degrading bacteria. The differences in fiber composition between WB and OB led to differences in nutrient digestibility and bacterial communities, which were ultimately reflected in energy metabolism. Enzyme supplementation improved nutrient digestibility as well as NE values for 27\% WB diets but not for other diets, which indicated that effects of enzyme were related to type and level of dietary fiber in diets.
\end{abstract}

Keywords: Bacterial community, Bacterial metabolites, Dietary fiber, Exogenous enzyme, Net energy, Pig

\section{Background}

Dietary fiber (DF) means carbohydrate polymers with ten or more monomeric units which are not hydrolyzed by the endogenous enzymes in the small intestine of humans [1]. The microbial conversions of DF to monosaccharides in the gut involves a number of principal reactions mediated by the carbohydrate-active enzymes. These enzymes are from specific members of the gut microbiota and have the function to cleave the glycosidic bonds between sugar monomers or between carbohydrate and non-carbohydrate structures. Major end products from these fermentations are the short-chain fatty acids (SCFA) [2], mainly acetate, propionate, and butyrate. Recent studies show that SCFA from microbial fermentation generates $11 \%$ to $24 \%$ of the total digestible energy (DE) as wheat bran (WB) level increases from $10 \%$ to $30 \%$ when fed to pigs [3]. It suggests that DF has a final impact on energy metabolism by shaping microbes and regulating SCFA production [4]. However, there is little information on the relationship between DF, gut bacteria, SCFA, and energy metabolism [5].

Oat bran $(\mathrm{OB})$ and WB are rich in DF that has negative effects on nutrient digestibility due to their antinutritive properties, but they may act as substances and energy sources to stimulate the intestinal microbiota [6]. Dietary fiber in $\mathrm{OB}$ is easier fermentable energy source for bacteria in the large intestine due to their lower proportion of lignified fiber types and higher proportion of soluble fiber types compared with fiber in WB. Specially, $\mathrm{OB}$ is rich in mixed linkages $\beta$-glucan which to a high degree is soluble and insoluble arabinoxylan [7]. By contrast, WB contained rich insoluble arabinoxylan. In the small intestine, $\beta$-glucan in $\mathrm{OB}$ is partly digested while arabinoxylan in OB or WB is hardly digested $[7,8]$. Accordingly, arabinoxylan is considered as one of the main components for DF in OB and WB to resist fermentation by bacteria in gastrointestinal tract. By adding xylanase to feeds, xylose backbone of arabinoxylan can be cleaved, thereby improving accessibility and utilization of nutrients in WB or $\mathrm{OB}$ diets and providing some fermentable oligosaccharides degraded from indigestible polysaccharides to intestinal bacteria [9]. Substrates available to intestinal bacteria and physiology of lumen change along gastrointestinal tract, and consequently intestinal bacteria are altered. Therefore, DF and exogenous enzymes, independently or in combination interaction are important means of regulating intestinal bacteria and ultimately affecting energy metabolism [4-6].

Therefore, we hypothesize that the diets supplemented with different fiber sources, with or without xylanase, could exert different impacts on nutrient digestibility and NE values of diets, and these differences were related to the activity of certain bacteria. Specially, our objectives are to determine effects of dietary characteristics and xylanase addition on nutrient digestibility, $\mathrm{NE}$ values of diets, fecal SCFA concentrations, and fecal bacterial communities of growing pigs.

\section{Methods}

\section{Experimental diets and enzyme}

As shown in Table 1, WB diets contained $12 \%$ or $27 \%$ WB which was added at the expense of corn and soybean meal. Oat bran diets contained $15 \%$ or $36 \%$ OB which was added at the expense of corn and soybean meal. Enzyme was added to one half of each diet at the rate of $40 \mathrm{~g} / 1000 \mathrm{~kg}$ diet to supply enzyme activity of $5000 \mathrm{U} / \mathrm{kg}$ complete feed (as-fed basis; Table 1). The enzyme was first mixed in the vitamin-mineral premix and then mixed with other ingredients. A total of 10 diets were fed to 60 growing pigs with a randomized complete block design. Diets were formulated on NE basis to meet estimated AA requirements for growing pigs [10]. Diets were formulated based on total dietary fiber (TDF) content in OB and WB. Specially, DF content (calculated values) between $36 \% \mathrm{OB}$ diets and $27 \% \mathrm{WB}$ diets or between $15 \%$ OB diets and $12 \%$ WB diets was similar. The xylanase used in the current study was endo- $1,4-\beta$ xylanase in granular form. The xylanase was provided by Bestzyme Co. Ltd. (Jinan, China) with enzyme activity of $200,000 \mathrm{U} / \mathrm{g}$.

\section{Animals and experimental procedure}

The animal procedures used in this experiment, including animal care and use, were approved by the Animal Care and Use Ethics Committee of China Agricultural University (Beijing, China). Sixty growing barrows (initial BW of $27.2 \pm 1.2 \mathrm{~kg}$ ) were allotted to 10 diets with 6 replicate pigs per diet in a randomized block design. The 
Table 1 Ingredients of experimental diets (as-fed basis) ${ }^{1}$

\begin{tabular}{|c|c|c|c|c|c|}
\hline \multirow[t]{2}{*}{ Item } & \multirow[b]{2}{*}{ Basal diet } & \multicolumn{4}{|c|}{ Test diets } \\
\hline & & $36 \%$ OB & $27 \%$ WB & $15 \% \mathrm{OB}$ & $12 \% \mathrm{WB}$ \\
\hline \multicolumn{6}{|l|}{ Ingredients, \% } \\
\hline Corn & 71.60 & 45.12 & 51.74 & 60.57 & 62.77 \\
\hline Soybean meal & 24.96 & 15.73 & 18.04 & 21.11 & 21.88 \\
\hline Oat bran & - & 36.00 & - & 15.00 & - \\
\hline Wheat bran & - & - & 27.00 & - & 12.00 \\
\hline Dicalcium phosphate & 0.90 & 0.90 & 0.90 & 0.90 & 0.90 \\
\hline Limestone & 0.90 & 0.90 & 0.90 & 0.90 & 0.90 \\
\hline Salt & 0.35 & 0.35 & 0.35 & 0.35 & 0.35 \\
\hline Premix ${ }^{2}$ & 0.50 & 0.50 & 0.50 & 0.50 & 0.50 \\
\hline Lys $\mathrm{HCl}$ & 0.50 & 0.32 & 0.36 & 0.42 & 0.44 \\
\hline Met & 0.07 & 0.04 & 0.05 & 0.06 & 0.06 \\
\hline Thr & 0.16 & 0.10 & 0.12 & 0.14 & 0.14 \\
\hline Val & 0.06 & 0.04 & 0.04 & 0.05 & 0.05 \\
\hline
\end{tabular}

${ }^{1} O B$ Oat bran, WB Wheat bran. The xylanase was provided by Bestzyme Co. Ltd. (Jinan, China). Enzyme was added to one half of each diet at the rate of $40 \mathrm{~g} /$ $1000 \mathrm{~kg}$ diet to supply enzyme activity of $5000 \mathrm{U} / \mathrm{kg}$ complete feed (as-fed basis)

${ }^{2}$ Vitamin-mineral premix supplied the following per kg of complete diet: vitamin A as retinyl acetate, $5512 \mathrm{IU}$; vitamin $\mathrm{D}_{3}$ as cholecalciferol, $2200 \mathrm{IU}$; vitamin $\mathrm{E}$ as $D L$-alpha-tocopheryl acetate, $30 \mathrm{IU}$; vitamin $\mathrm{K}_{3}$ as menadione nicotinamide bisulfite, $2.2 \mathrm{mg}$; vitamin $\mathrm{B}_{12}$, $27.6 \mu \mathrm{g}$; riboflavin, 4 mg; pantothenic acid as $D L$-calcium pantothenate, $14 \mathrm{mg}$; niacin, $30 \mathrm{mg}$; choline chloride, $400 \mathrm{mg}$; folacin, $0.7 \mathrm{mg}$; thiamin as thiamine mononitrate, $1.5 \mathrm{mg}$; pyridoxine as pyridoxine hydrochloride, 3 mg; biotin, $44 \mu \mathrm{g} ; \mathrm{Mn}$ as $\mathrm{MnO}, 40 \mathrm{mg} ; \mathrm{Fe}$ as $\mathrm{FeSO}_{4} \cdot \mathrm{H}_{2} \mathrm{O}, 75 \mathrm{mg}$; $\mathrm{Zn}$ as $\mathrm{ZnO}, 75 \mathrm{mg} ; \mathrm{Cu}$ as $\mathrm{CuSO}_{4} \cdot 5 \mathrm{H}_{2} \mathrm{O}, 25 \mathrm{mg} ; \mathrm{I}$ as $\mathrm{Kl}, 0.3 \mathrm{mg} ; \mathrm{Se}^{2}$ as $\mathrm{Na}_{2} \mathrm{SeO}$, $0.3 \mathrm{mg}$

experiment was conducted in 10 consecutive periods using 6 similar open-circuit respiration chambers as described by Lyu et al. [11]. Each pig was used for one 20$\mathrm{d}$ period. During each period, 6 pigs were allowed $14 \mathrm{~d}$ to adapt to diets in metabolic cages followed by $6 \mathrm{~d}$ in respiration chambers to measure heat production (HP). Pigs were fed their assigned diets at $2.3 \mathrm{MJ} \mathrm{ME} /(\mathrm{kg}$ $\left.\mathrm{BW}^{0.6} \cdot \mathrm{d}\right)$ on basis of $\mathrm{BW}$ measured on $\mathrm{d} 0,7$, and 14 [12]. Pigs were fed equal-sized dried meals twice daily at 08:30 and 15:30 $\mathrm{h}$ in mash form and had free access to water via a low-pressure nipple drinker. Urine was collected in buckets containing $50 \mathrm{~mL}$ of $6 \mathrm{~mol} / \mathrm{L} \mathrm{HCl}$. From d 15 to 19 of each period, total feces and urine were collected from the chambers once daily at 8:30 h and then stored at $-20^{\circ} \mathrm{C}$. On d 19 (from 7:30 to 9:00 h) of each period, six freshly voided fecal samples from each dietary treatment were collected to measure SCFA concentrations and bacterial community. Fecal samples were acquired using a $5-\mathrm{mL}$ centrifuge tube, put in liquid nitrogen and then were stored at $-80^{\circ} \mathrm{C}$. Diet samples were collected in each collection period and then stored at $-20{ }^{\circ} \mathrm{C}$. At the end of experiment, diet samples were mixed and subsampled based on treatments to measure xylanase activity. From d 19 to 20 of each period, pigs were fasted.

The design of 6 open-circuit respiration chambers were reported by van Milgen et al. [13] and Lyu et al. [11]. Volume of each chamber was approximately 7.8 $\mathrm{m}^{3}$, and relative humidity in chamber was controlled at $70 \%$. During the feeding period, the temperature was
$22{ }^{\circ} \mathrm{C}$, and it was increased to $24^{\circ} \mathrm{C}$ on the fasted day. The measurement range of analyzers was $19.5 \%$ to $21 \%$ for $\mathrm{O}_{2}, 0$ to $1 \%$ for $\mathrm{CO}_{2}, 0$ to $0.1 \%$ for $\mathrm{CH}_{4}$, and 0 to $0.1 \%$ for $\mathrm{NH}_{3}$ with a sensitivity of $0.2 \%$ within the measurement range.

\section{Sample preparation and chemical analyses}

Diets were collected during each feeding period to measure chemical composition. Fecal samples were oven-dried for $72 \mathrm{~h}$ at $65{ }^{\circ} \mathrm{C}$ and were ground through a $1-\mathrm{mm}$ screen for further chemical analysis. Urine samples were pooled separately within pig.

Xylanase activity in diets was analyzed using spectrophotometric method as described by Lærke et al. [14]. The chemical analyses of ingredients and diets included dry matter (DM, method 930.15) [15], crude protein (CP, method 984.13) [15], ether extract (EE) [16], ash (method 942.05) [15], Ca (method 968.08) [15], and P (method 946.06) [15]. Gross energy (GE) of ingredients, diets, feces, and urine (UE) was determined using an isoperibol calorimeter (Parr 6300 Calorimeter, Moline, IL USA). The neutral detergent fiber (NDF) and acid detergent fiber (ADF) in ingredients, diets, and feces were determined using a fiber analyzer (model A220 fiber analyzer; Ankom Technology, Macedon, NY, USA) following a procedure by Van Soest et al. [17]. The combination of enzymatic and gravimetric procedures reported by Prosky et al. [18] was used to measure TDF, insoluble dietary fiber (IDF) and soluble dietary fiber (SDF) in ingredients and diets. Non-starch 
polysaccharides (NSP) and their constituent sugars in $\mathrm{OB}$ and WB were determined based on alditol acetates by gas-liquid chromatography (Aglilent GC 6890, USA) with a flow of $20 \mathrm{~mL} / \mathrm{min}$ and split $40: 1$. The column temperature was $220^{\circ} \mathrm{C}$ and the injector and detector temperature were $250^{\circ} \mathrm{C}$.

Fecal SCFA concentrations were measured using the method reported by Liu et al. [19]. About $0.5 \mathrm{~g}$ of fecal sample was placed in a centrifuge tube with $8 \mathrm{~mL}$ of distilled water. The mixture was centrifuged at $13,000 \mathrm{r} /$ min for $10 \mathrm{~min}$ to obtain the supernatant. One milliliter of supernatant was diluted 1:50 with water and filtered through a $0.22-\mathrm{mm}$ nylon membrane filter. Filtered supernatant was analyzed using high-performance ion exchange chromatograph (ICS 3000 Dionex, USA).

\section{Analysis for bacterial microbiota by $16 \mathrm{~S}$ RNA sequences}

Bacterial DNA was extracted from fecal samples using the DNA Kit (Omega Bio-tek, Norcross, GA, USA). NanoDrop 2000 UV-VIS spectrophotometer (Thermo Scientific, Wilmington, USA) was used to determine DNA concentration and purification. Quality of DNA was assessed by $1 \%$ agarose gel electrophoresis. The V3V4 hypervariable regions of the bacteria 16S rRNA gene were amplified with primers 338F (5'-ACTCCTACGG GAGGCAGCAG-3') and 806R (5'-GGACTACHVGGG TWTCTAAT-3') by thermocycler PCR system (GeneAmp 9700, ABI, USA). The PCR products were extracted from a $2 \%$ agarose gel and then purified using the AxyPrep DNA Gel Extraction Kit (Axygen Biosciences, Union City, CA, USA) and quantified using QuantiFluor ${ }^{\mathrm{rm}-}-\mathrm{ST}$ (Promega, USA).

Pooled and purified amplicons in equimolar and paired-end were sequenced $(2 \times 300 \mathrm{bp})$ on an Illumina MiSeq platform (Illumina, San Diego,USA) according to the standard protocols introduced by Majorbio BioPharm Technology Co. Ltd. (Shanghai, China). Raw fastq files were quality-filtered by Trimmomatic and merged by FLASH.

Operational taxonomic units (OTU) were clustered with 0.97 similarity cutoff using UPARSE (version 7.1 http://drive5.com/uparse/). The taxonomy of each $16 \mathrm{~S}$ rRNA gene sequence was analyzed by Ribosomal Database Project (RDP) Classifier algorithm (http://rdp.cme. msu.edu/) against the Silva (SSU123) 16S rRNA database using confidence threshold of 0.70 .

\section{Calculations}

The apparent total tract digestibility (ATTD) of nutrients, total heat production (THP), retained energy (RE), and NE values in diets were calculated using the following equations $[12,20]$ : $\mathrm{ATTD}=[(\mathrm{Fi}-\mathrm{Ff}) / \mathrm{Fi}] \times 100 \%$, where Fi was total intake of energy (kJ) or nutrients $(\mathrm{g})$, and $\mathrm{Ff}$ was the total fecal output of energy $(\mathrm{kJ})$ or nutrients (g); $\quad$ THP $=16.18 \times \mathrm{O}_{2}+5.02 \times \mathrm{CO}_{2}-2.17 \times$ $\mathrm{CH}_{4}-5.99 \times$ urinary nitrogen excretion, where THP was in kilojoule, $\mathrm{O}_{2}$ was oxygen consumption in liters, $\mathrm{CO}_{2}$ was carbon dioxide production in liters, and $\mathrm{CH}_{4}$ was methane production in liters. Urinary nitrogen excretion was in grams. The data collection for $\mathrm{O}_{2}, \mathrm{CO}_{2}$, and $\mathrm{CH}_{4}$ used the standard procedure as described by Lyu et al. [11]. In addition, to eliminate the effects of activity of pigs, FHP was calculated using the equation for THP with gas data obtained from $22: 30 \mathrm{~h}(\mathrm{~d} 19)$ to $06: 30 \mathrm{~h}(\mathrm{~d}$ 20). To calculate the FHP throughout the day, the 8-h FHP was extrapolated to a 24-h period; $\mathrm{RE}=(\mathrm{ME}$ intake - THP), where RE was in kilojoule, and ME intake and THP were in kilojoule per day. The retained energy as protein $\left(R E_{\mathrm{P}}\right)$ was calculated based a recognized formula (nitrogen $\times 6.25 \times 23.84, \mathrm{~kJ} / \mathrm{g}$ ), whereas $\mathrm{RE}$ as lipids $\left(R_{L}\right)$ was calculated as the difference between $R E$ and $\mathrm{RE}_{\mathrm{P}}[21] ; \mathrm{NE}=(\mathrm{RE}+\mathrm{FHP}) / \mathrm{DM}$ intake, where NE was in kilojoule per kilogram DM; RE and FHP were in kilojoule per day and DM intake was in kilograms per day. The DE of diets was calculated by subtracting energy lost in the feces from GE. The ME of diets was calculated by subtracting energy lost in the urine and methane from DE. Energy lost as methane $\left(\mathrm{CH}_{4} \mathrm{E}\right)$ was calculated assuming $1 \mathrm{~L}$ of $\mathrm{CH}_{4}$ contained $39.54 \mathrm{~kJ}$ energy [20]. The DE, metabolizable energy (ME) and $\mathrm{NE}$ content of $\mathrm{OB}$ and $\mathrm{WB}$ in diets containing $36 \% \mathrm{OB}$ and $27 \% \mathrm{WB}$ were calculated using the difference method, respectively [22].

\section{Statistical analysis}

All data of the experiment were averaged per pig and were analyzed using the MIXED procedure of SAS (SAS Institute Inc., Cary, NC, USA). The experimental unit was the individual pig. Diet, enzyme and their interactions were treated as the fixed effects and collection, period and chamber as random effects. The LSMEANS statement with Tukey's adjustment was used to separate mean values. To eliminate the effect of ME intake, the THP and RE data were adjusted for each collection period by covariance analysis for ME intake of $2322 \mathrm{~kJ} /$ $\left(\mathrm{kg} \mathrm{BW}^{0.60} \cdot \mathrm{d}\right)$ (mean value for the experiment). A mixture of two fecal samples was used to analyze bacterial communities. Bacterial diversity was analyzed using standardized OTU reads with the help of $\mathrm{R}$ software. Relative abundance of bacteria at phylum and family levels were showed as bar plots. Heatmap was used to analyze bacterial communities at genus level. The linear discriminant analysis (LDA) effect size (LEfSe) algorithm was adopted to classify abundances of differential bacteria from phylum to genus. The logarithmic LDA value of 2.0 was used to be the criterion. The comparative analysis between OB-based diets $(n=12)$ and WB-based $(n=12)$ diets or between high-fiber diets (36\% OB diets 
and 27\% WB diets; $n=12)$ and low-fiber diets (15\% OB diets and 12\% WB diets; $n=12$ ), was conducted based on the method of Welch's t-test. If $P<0.05$, it was considered significant difference. The contrast for data obtained in the enzyme-supplemented group to those obtained in enzyme-free group was also calculated using same method to validate the enzyme effect.

\section{Results}

\section{Chemical composition of ingredients and diets}

Wheat bran contained more content of NDF, ADF, hemicellulose, and IDF but lower content of SDF than OB (Supplementary Table S1). For NSP composition, OB contained more soluble NSP (7.8\% vs. $3.9 \%)$, especially glucose. By contrast, WB contained more insoluble NSP (28.7\% vs. $15.6 \%)$, mainly arabinose and xylose. In addition, OB contained more content of CP $(22.0 \%$ vs. $15.1 \%)$, starch $(28.1 \%$ vs. $8.2 \%)$ and $\mathrm{EE}(7.6 \%$ vs. $3.2 \%)$ than WB. Dietary fiber content was similar between $36 \%$ OB diets and 27\% WB diets or between 15\% OB diets and $12 \%$ WB diets, which was consistent to the study design (Table 1 and Table 2).

\section{Nutrient digestibility, nitrogen balance, and energy metabolism}

There were interactions $(P<0.05)$ between diet and enzyme supplementation on ATTD of DM, GE, CP and ADF (Table 3). In the enzyme-free treatments, 27\% WB diets had lower $(P<0.05)$ ATTD of DM, GE, CP, ADF and $\mathrm{OM}$ than $\mathrm{OB}$ diets and basal diets. Pigs fed 27\% WB diets had lower $(P<0.05)$ ATTD of DM, CP and ADF than those fed $12 \%$ WB diets. By contrast, there were no differences on the ATTD of nutrients between $36 \%$ OB diets and 15\% OB diets. The nitrogen output from feces was greater $(P<0.05)$ in $27 \%$ WB diets than that in basal diets and 15\% OB diets. Total nitrogen retention was not affected by dietary characteristics. Supplementation of enzyme improved $(P<0.05)$ ATTD of DM, CP and $\mathrm{ADF}$ in $27 \% \mathrm{WB}$ diets, and no differences were observed for the enzyme effects in other dietary treatments.

No interactions between diet and enzyme on the energy retention were found (Supplementary Table S2). The THP, FHP, and RE data were not affected by dietary characteristics. Enzyme supplementation improved $(P<$ $0.05) \mathrm{ME}$ intake in pigs. There were interactions $(P<$ 0.05 ) between diet and enzyme supplementation on ME and NE content of diets (Table 4). The NE:ME ratios and ME:DE ratios were not affected by diets and enzyme supplementation. The DE content was lower $(P<0.05)$ in pigs fed WB-based diets compared with those fed OB-based diets and basal diets. In enzyme-free dietary groups, 27\% WB diets had lower $(P<0.05) \mathrm{ME}$ and NE values than other diets. There were no differences for the ME and NE values between 36\% OB diets and 12\% $\mathrm{OB}$ diets. Enzyme addition improved the NE values $(P<$ $0.05)$ in pigs fed 27\% WB diets. Enzyme addition improved $(P<0.05) \mathrm{ME}$ and NE content of WB from 11.75 to 13.02 , and 8.77 to 10.04 (MJ/kg of feed $\mathrm{DM})$ (Table 5).

\section{Short-chain fatty acids in feces}

The total SCFA were considered as the sum of lactate, formate, acetate, propionate, isobutyrate, butyrate, isovalerate, and valerate, but the lactate and formate were not listed because of their minor concentrations (Table 6). The concentrations of SCFA were expressed in $\mathrm{mg} / \mathrm{kg}$ feed DM. There were interactions $(P<0.05)$ between diet and enzyme supplementation on concentrations of

Table 2 Chemical composition of experimental diets (DM basis) ${ }^{1}$

\begin{tabular}{|c|c|c|c|c|c|c|c|c|c|c|}
\hline \multirow[t]{2}{*}{ tem $^{2}$} & \multicolumn{2}{|c|}{ Basal diet } & \multicolumn{2}{|c|}{$36 \% \mathrm{OB}$} & \multicolumn{2}{|c|}{$27 \%$ WB } & \multicolumn{2}{|c|}{$15 \% \mathrm{OB}$} & \multicolumn{2}{|c|}{$12 \% \mathrm{WB}$} \\
\hline & - & + & - & + & - & + & - & + & - & + \\
\hline \multicolumn{11}{|l|}{ Analyzed composition } \\
\hline GE, MJ/kg DM & 18.21 & 18.37 & 19.00 & 19.10 & 18.62 & 18.65 & 18.66 & 18.58 & 18.60 & 18.45 \\
\hline $\mathrm{CP}, \% \mathrm{DM}$ & 19.5 & 19.7 & 21.1 & 21.6 & 18.5 & 18.9 & 20.3 & 20.4 & 19.8 & 19.0 \\
\hline Ether extract, \% DM & 3.6 & 3.5 & 5.9 & 5.6 & 3.8 & 4.1 & 4.6 & 4.8 & 3.9 & 4.0 \\
\hline$N D F, \% D M$ & 10.3 & 10.9 & 17.9 & 15.7 & 19.4 & 19.6 & 12.1 & 11.6 & 14.2 & 14.5 \\
\hline $\mathrm{ADF}, \% \mathrm{DM}$ & 3.9 & 4.1 & 5.3 & 5.1 & 6.1 & 6.4 & 4.4 & 4.2 & 5.0 & 5.0 \\
\hline TDF, \% DM & 14.9 & 14.6 & 23.6 & 24.3 & 24.1 & 23.7 & 18.4 & 19.0 & 18.9 & 18.3 \\
\hline $\mathrm{SDF}, \% \mathrm{DM}$ & 2.9 & 2.7 & 7.8 & 7.7 & 2.8 & 2.9 & 4.9 & 5.0 & 2.8 & 2.5 \\
\hline IDF, \% DM & 12.0 & 11.9 & 15.8 & 16.6 & 21.3 & 20.7 & 13.6 & 14.1 & 16.1 & 15.8 \\
\hline Ash, \% DM & 4.8 & 4.9 & 5.5 & 6.0 & 5.6 & 5.6 & 5.1 & 5.2 & 5.1 & 5.3 \\
\hline Enzyme activity, U/kg & - & 5325 & - & 5120 & - & 4876 & - & 4795 & - & 5145 \\
\hline
\end{tabular}

${ }^{1}$ Data are the means of two replicates of analyzed values

${ }^{2} O B$ Oat bran; WB Wheat bran; GE Gross energy; DM Dry matter; $C P$ Crude protein; NDF Neutral detergent fiber; $A D F$ Acid detergent fiber; TDF Total dietary fiber; $S D F$ Soluble dietary fiber; IDF Insoluble dietary fiber. The - and + symbol represents enzyme-free diets and enzyme addition diets, respectively 







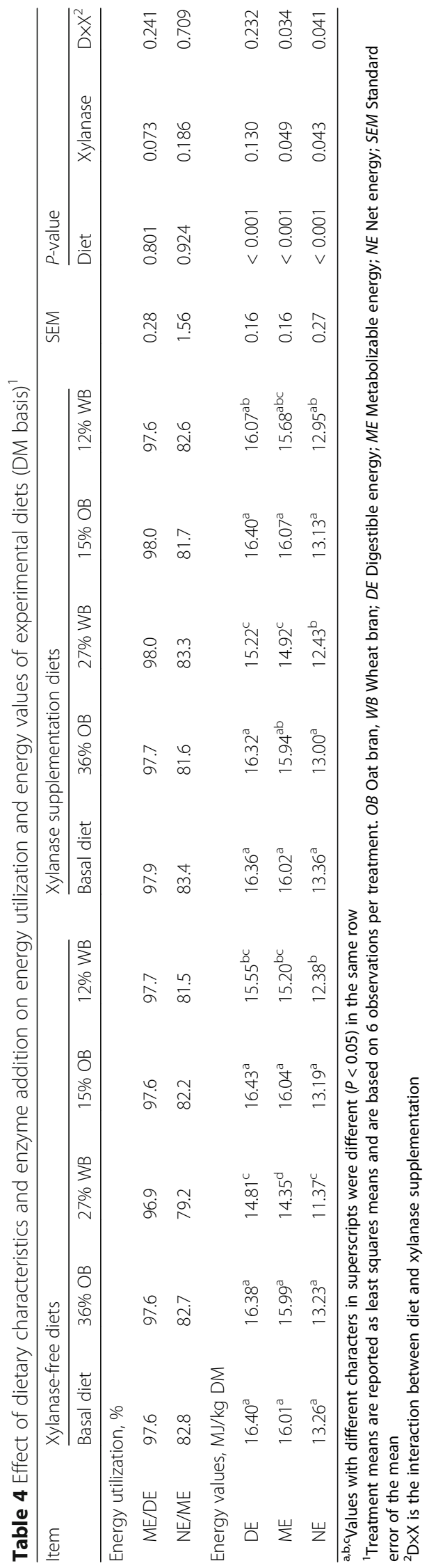


Table 5 Nutrient digestibility and energy values of the oat bran and wheat bran

\begin{tabular}{|c|c|c|c|c|c|c|}
\hline \multirow[t]{3}{*}{ Item $^{2}$} & \multicolumn{4}{|c|}{ Ingredient $^{3}$} & \multirow[t]{3}{*}{ SEM } & \multirow[t]{3}{*}{$P$-value } \\
\hline & \multicolumn{2}{|c|}{ Oat bran } & \multicolumn{2}{|c|}{ Wheat bran } & & \\
\hline & - & + & - & + & & \\
\hline \multicolumn{7}{|l|}{ ATTD, \% } \\
\hline Gross energy & $83.0^{\mathrm{a}}$ & $81.5^{\mathrm{a}}$ & $63.3^{c}$ & $71.8^{\mathrm{b}}$ & 6.3 & 0.045 \\
\hline Crude protein & $83.1^{\mathrm{a}}$ & $79.5^{\mathrm{ab}}$ & $52.4^{c}$ & $77.5^{\mathrm{b}}$ & 6.8 & 0.034 \\
\hline Neutral detergent fiber & $73.6^{\mathrm{a}}$ & $65.3^{\mathrm{ab}}$ & $47.0^{c}$ & $62.8^{\mathrm{b}}$ & 7.8 & 0.020 \\
\hline Acid detergent fiber & $52.2^{\mathrm{a}}$ & $43.8^{\mathrm{b}}$ & $28.0^{c}$ & $52.8^{\mathrm{a}}$ & 4.7 & 0.031 \\
\hline Organic matter & $83.7^{\mathrm{a}}$ & $83.4^{\mathrm{a}}$ & $58.0^{c}$ & $75.0^{\mathrm{b}}$ & 5.0 & 0.044 \\
\hline \multicolumn{7}{|l|}{ Energy utilization, \% } \\
\hline ME/DE & 97.7 & 97.2 & 98.4 & 96.3 & 3.6 & 0.405 \\
\hline NE/ME & 77.5 & 79.6 & 74.7 & 77.1 & 5.4 & 0.223 \\
\hline \multicolumn{7}{|l|}{ Energy values, MJ/kg DM } \\
\hline DE & $16.80^{\mathrm{a}}$ & $16.50^{\mathrm{a}}$ & $11.93^{\mathrm{b}}$ & $13.53^{\mathrm{ab}}$ & 0.72 & 0.122 \\
\hline ME & $16.41^{\mathrm{a}}$ & $16.04^{\mathrm{a}}$ & $11.75^{\mathrm{c}}$ & $13.02^{b}$ & 0.80 & 0.033 \\
\hline NE & $12.72^{\mathrm{a}}$ & $12.76^{\mathrm{a}}$ & $8.77^{c}$ & $10.04^{b}$ & 0.95 & 0.046 \\
\hline
\end{tabular}

$a, b, c$ Values with different characters in superscripts were different $(P<0.05)$ in the same row

${ }^{1}$ Treatment means are reported as least squares means and are based on 6 observations per treatment

${ }^{2}$ The apparent total tract digestibility (ATTD) of nutrient and energy values of oat bran and wheat bran were calculated using difference method in diets

containing $36 \%$ oat bran or $27 \%$ wheat bran. DE Digestible energy; ME Metabolizable energy; NE Net energy; SEM Standard error of the mean

${ }^{3}$ The - and + symbol represents enzyme-free dietary treatment and enzyme addition dietary treatment, respectively

acetate, propionate, butyrate, and isovalerate. In the enzyme-free dietary groups, pigs fed WB-based diets excreted more $(P<0.05)$ acetate and propionate and total SCFA in feces than those fed a basal diet. The acetate and propionate concentrations in feces were greater $(P<$ 0.05 ) in pigs fed $27 \%$ WB diets compared with those fed $36 \%$ OB diets and a basal diet. The acetate concentrations in feces were greater $(P<0.05)$ in pigs fed $27 \% \mathrm{WB}$ diets compared with those fed $12 \%$ WB diets. By contrast, the increase of fiber level in OB diets did not affect the acetate and propionate concentrations in fecal samples. Enzyme supplementation increased $(P<0.05)$ acetate, propionate, isobutyrate and total SCFA excretion in pigs fed $12 \% \mathrm{WB}$ diets.

\section{The richness and biodiversity of bacterial communities}

The indices of Chao and Shannon at the OTU level were used to elevate bacterial richness and diversity. The two indices were not affected by fiber source, fiber level or enzyme addition (Fig. 1). The bacterial composition was presented at the phylum, family, and genus levels, respectively (Fig. 2 and Supplementary Fig. S1). Firmicutes and Bacteroidetes, were the two main phyla of bacteria in the fecal samples of growing pigs (Supplementary Fig. S1A). The predominant families in Firmicutes consisted of Ruminococcaceae, Lachnospiraceae, Veillonellaceae, and Christensenellaceae, while Prevotellaceae, Bacteroidales_S24-7_group, and Erysipelotrichaceae were the predominant families in Bacteridetes (Supplementary Fig. S1B).
Cladogram of LEfSe showed all differential bacteria from phylum to genus level (Fig. 3 and Fig. 4). The relative abundances of main kinds of bacteria were greater $(P<$ 0.05 ) in high-fiber diets than those in low-fiber diets (Fig. 3a), including Marvinbryantia, [Eubacterium]_hallii_ group, Lachnospiraceae_FCSO20_group and Lachnospiraceae_ND3007_group, which belonged to family Lachnospiraceae, and Bifidobacterium, which belonged to family Bifidobacteriaceae. The abundances of Senegalimassilia and norank_f_Peptococcaceae were decreased in highfiber diet than those in low-fiber diets $(P<0.05)$.

The abundance of Anaerotruncus, Ruminococcaceae UCG_014, and Solobacterium was greater $(P<0.05)$ in pigs fed $\mathrm{OB}$ diets than pigs fed $\mathrm{WB}$, which resulted in an increase $(P<0.05)$ in the population of phylum Firmicutes (Fig. 3b). Pigs fed the WB diets had greater $(P<0.05)$ proportion of phylum Bacteroidetes, family Prevotellaceae and order Bacteroidia compared to those fed the OB diets, which was due to increased relative abundances of unclassified_f_Prevotellaceae, Prevotella_1, and dgA_11_gut_group $(P<0.05)$. The increased abundance of Succinivibrio $(P<$ $0.05)$ led to greater proportion of Spirochaetae $(P<0.05)$ in pigs fed WB diets compared with those fed $\mathrm{OB}$ diets.

When pigs were fed diets with $36 \%$ OB (Fig. 4a), enzyme addition decreased $(P<0.05)$ the relative abundances of $u n-$ classified_f_Lachnospiraceae, Lachnospiraceae_NK4A136_ group, Lachnospiraceae_FCSO20_group, Coprococcus_3, Marvinbryantia, Eubacterium_hallii_group, and Blautia belonging to family Lachnospiraceae. Meanwhile, xylanase addition decreased $(P<0.05)$ the relative abundances of 


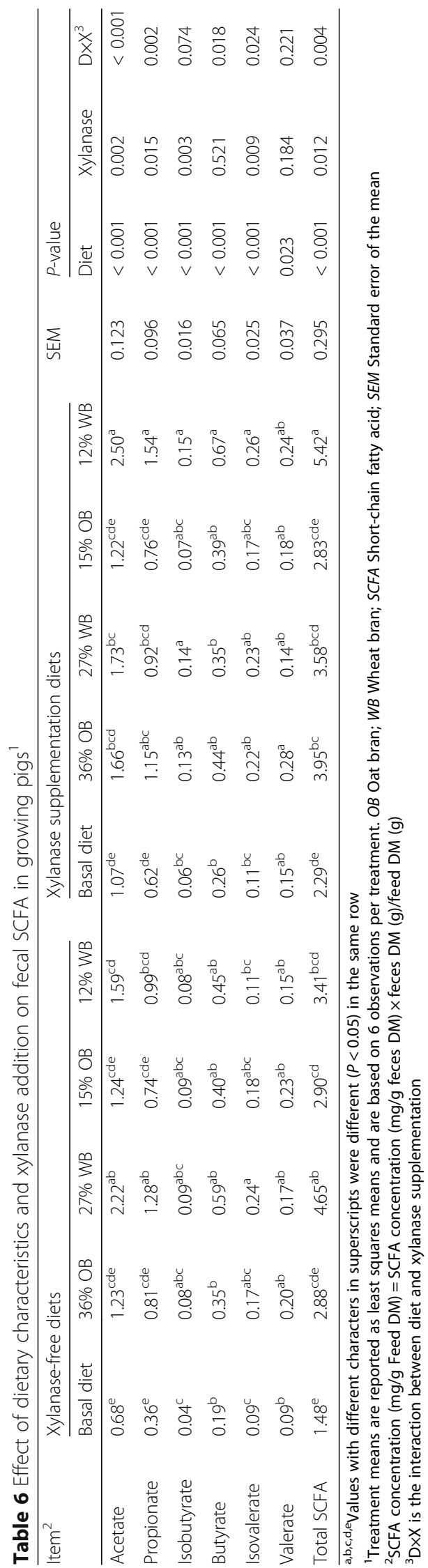




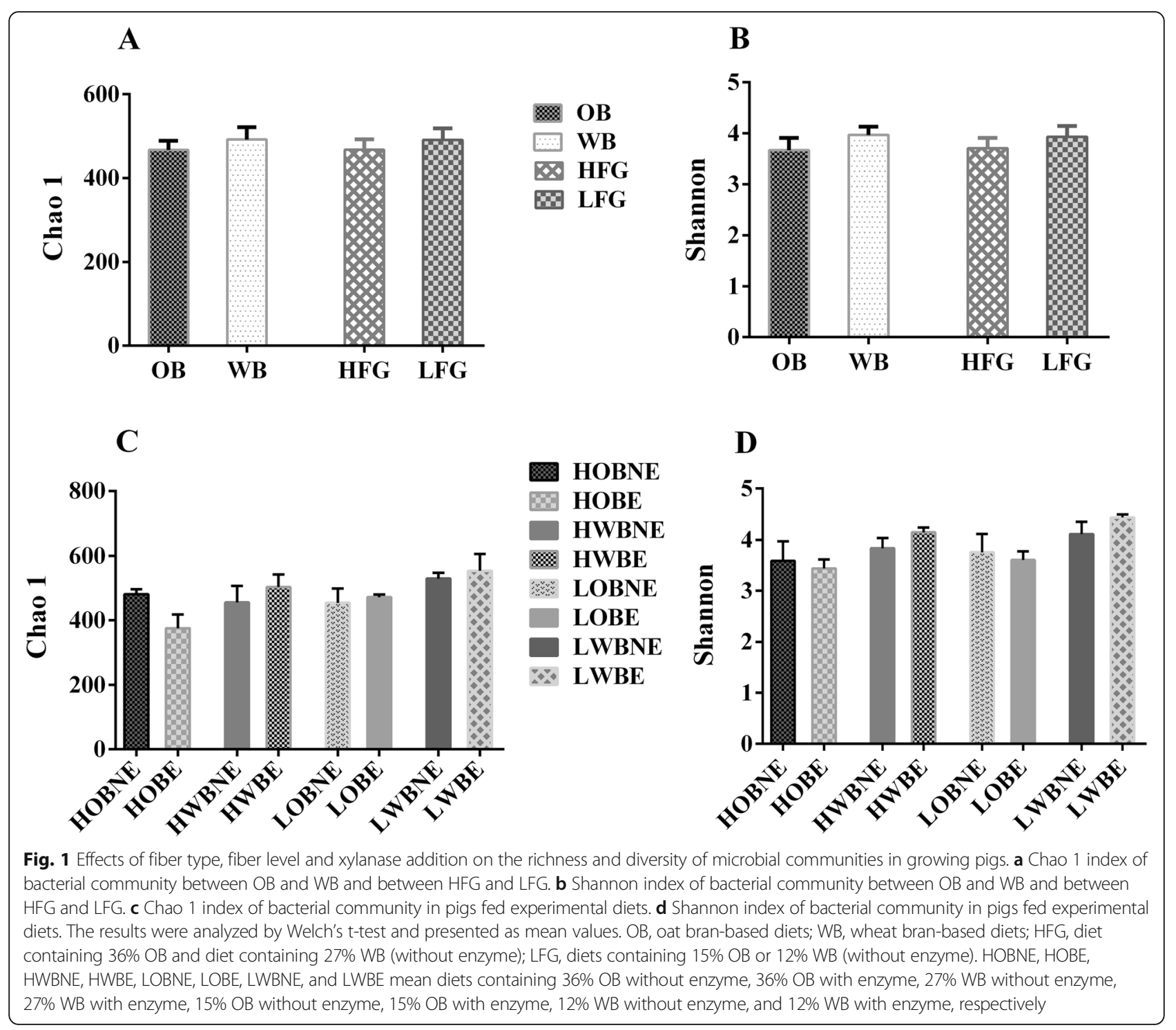

Ruminococcaceae_UCG_005, Ruminococcus_1, Faecalibacterium, and Candidatus_Saccharimonas and increased $(P<$ $0.05)$ the abundances of Escherichia_Shigella and Olsenella. When pigs were fed the diet with 27\% WB (Fig. 4b), enzyme addition increased $(P<0.05)$ the relative abundances of Christensenellaceae_R-7_group and Ruminococcaceae UCG_002, thereby increasing $(P<0.05)$ the abundances of families Christensenellaceae and Ruminococcaceae. Enzyme addition decreased $(P<0.05)$ the relative abundances of genrea Eubacterium_ruminantium_group and Lactobacillus and decreased $(P<0.05)$ the abundances of families Lachnospiraceae, Bacteroidales, and Lactobacillaceae when pigs were fed diet with $27 \% \mathrm{WB}$. When pigs were fed the diet containing 12\% OB (Fig. 4c), enzyme addition improved $(P<0.05)$ the relative abundances of Blautia, Catenibacterium, and Prevotella_1. When pigs were fed diet with 12\% WB (Fig. 4d), enzyme addition increased
$(P<0.05)$ the relative abundances of Faecalibacterium, Ruminococcaceae_UCG_013, Ruminococcaceae_UCG_014, thereby increasing $(P<0.05)$ the abundances of family Ruminococcaceae. In addition, enzyme addition in diet with 12\% WB decreased $(P<0.05)$ the abundance of Chlamydia.

\section{Discussion}

The high inclusion levels of DF in 36\% OB diets and 27\% WB diets decreases ATTD of DM and GE compared with basal diets. The results are consistent with the previous studies that report DF negatively affects nutrient digestibility due to their anti-nutritive effects [23-25]. The differences in chemical composition of OB and WB lead to different results on nutrient digestibility, SCFA concentrations and abundance of bacteria in feces, and energy values in diets. Wheat bran contains a higher proportion of insoluble lignified fiber and is therefore 
A

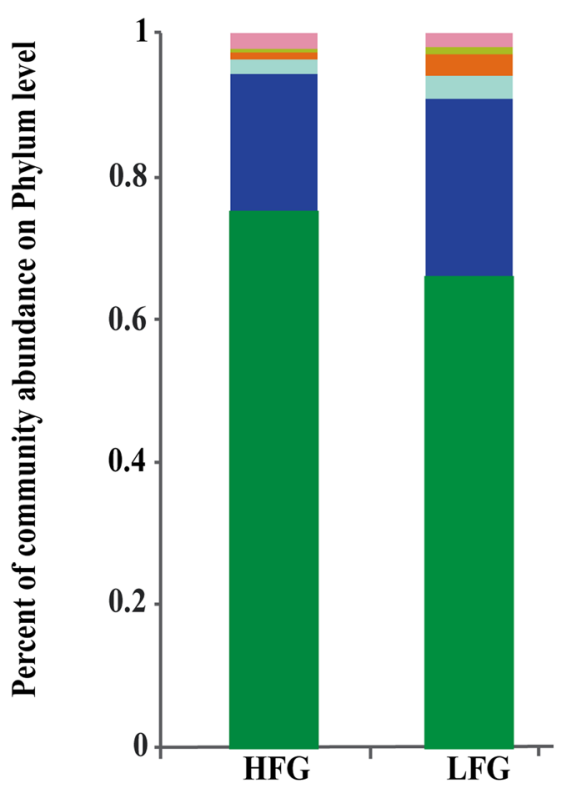

C

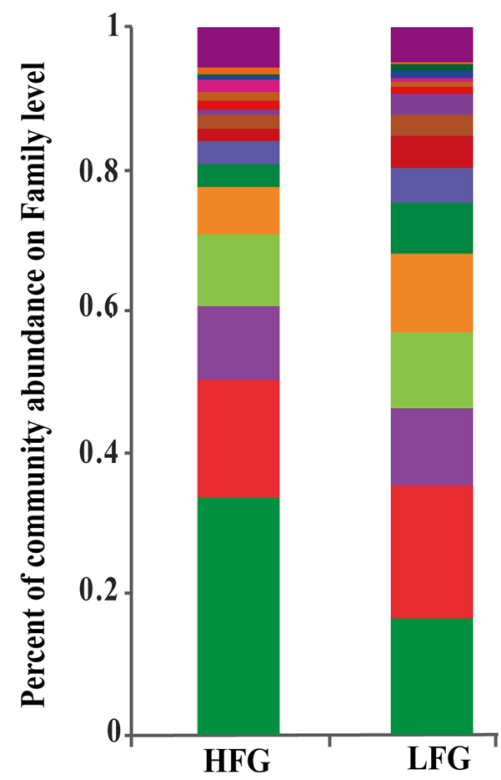

B

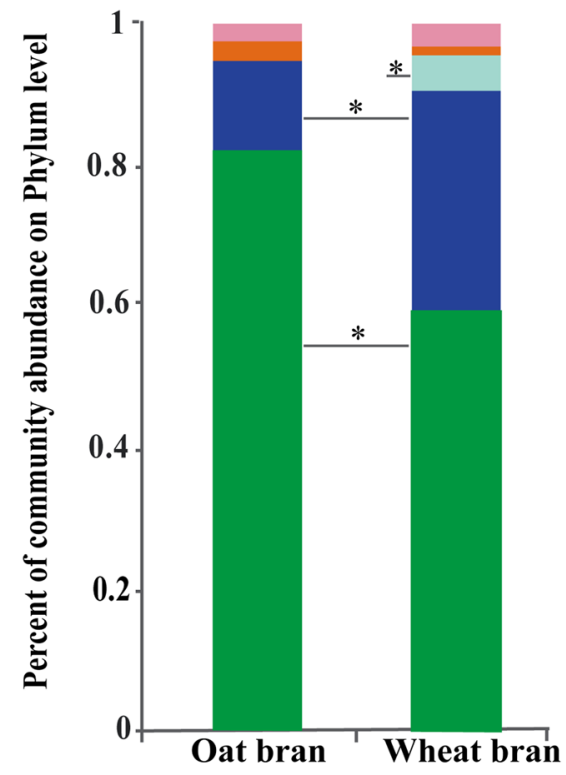

D

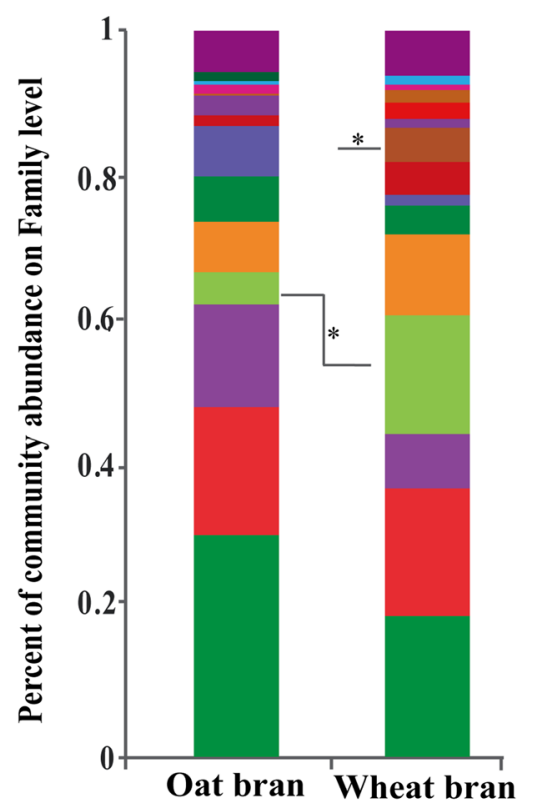

Fig. 2 Effects of fiber level and type fecal on microbial community structure in growing pigs. Distribution of fecal bacteria on the phylum (a) and family (c) levels in pigs fed high or low-fiber diets. Distribution of fecal bacteria on the phylum (b) and family (d) levels in pigs fed OB or WB based diets. The Welch's t test was applied to identify the differences in the relative abundance of gut microbiota between two groups, and one asterisk means $P<0.05$. Phyla and families with proportions less than $1 \%$ are not listed. HFG, diet containing $36 \%$ oat bran or $27 \%$ wheat bran (without enzyme); LFG, diets containing 15\% oat bran or 12\% wheat bran (without enzyme)

less degraded than DF in OB. As a result, pigs fed $36 \%$ $\mathrm{OB}$ diets have greater nutrient digestibility compared with those fed 27\% WB diets. Meanwhile, 27\% WB diets contain lower nutrient (DM and $\mathrm{CP}$ ) digestibility than $12 \%$ WB diets. However, nutrient digestibility is not affected by inclusion levels of OB. The results confirm DF in WB has greater negative effects on nutrient digestibility than that in $\mathrm{OB}$. In addition, $\mathrm{OB}$ contains more starch, $\mathrm{CP}$, and $\mathrm{EE}$ content, which is the main reason why $\mathrm{OB}$ has greater $\mathrm{NE}$ values than WB. Wheat 

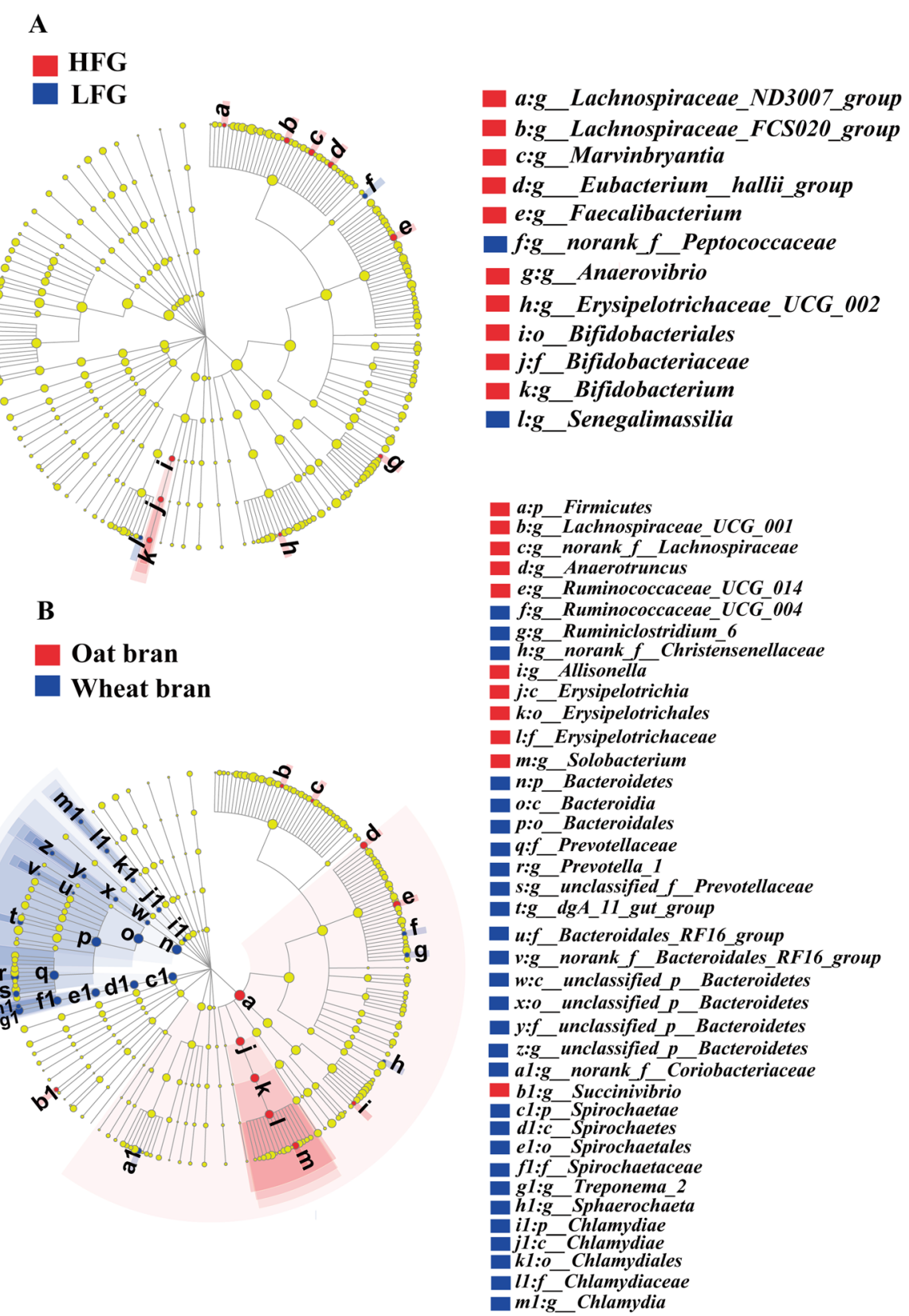

Fig. 3 Effects of fiber level and type on differential bacteria from genus to phylum. a Differential bacteria $(P<0.05)$ between HFG and LFG. $\mathbf{b}$ Differential bacteria $(P<0.05)$ between oat bran and wheat bran treatments. HFG, diet containing 36\% oat bran and diet containing $27 \%$ wheat bran (without enzyme); LFG, diets containing 15\% oat bran or 12\% wheat bran (without enzyme); oat bran, oat bran-based diets; wheat bran, wheat bran-based diets

bran has a typical NSP composition of gramineous grain by-products that mainly consists of insoluble arabinoxylan and cellulose [26], whereas OB is rich in mixed linkages $\beta$-glucan which to a high degree is soluble and insoluble arabinoxylan. In addition, only trace levels of cellulose are found in $\mathrm{OB}$ [7]. In the small intestine, $\beta$ glucan in $\mathrm{OB}$ is partly digested while arabinoxylan in $\mathrm{OB}$ or WB is hardly digested $[7,8]$. In pigs, fiber in $\mathrm{OB}$ was readily fermented by bacteria along gastrointestinal tract
[27]. By contrast, most of DF in WB enters hindgut to contribute to microbial fermentation and SCFA generation. Therefore, supplementation of diets with high levels WB rather than OB caused fermentation of fiber and undigested nutrients to shift from the small intestine to hindgut, thereby contributing to growth of fiber-degrading bacteria in hindgut of pigs $[27,28]$. In the current study, the abundances of Firmicutes in pigs fed OB diets are greater while the abundances of Bacteroidetes in WB diets 


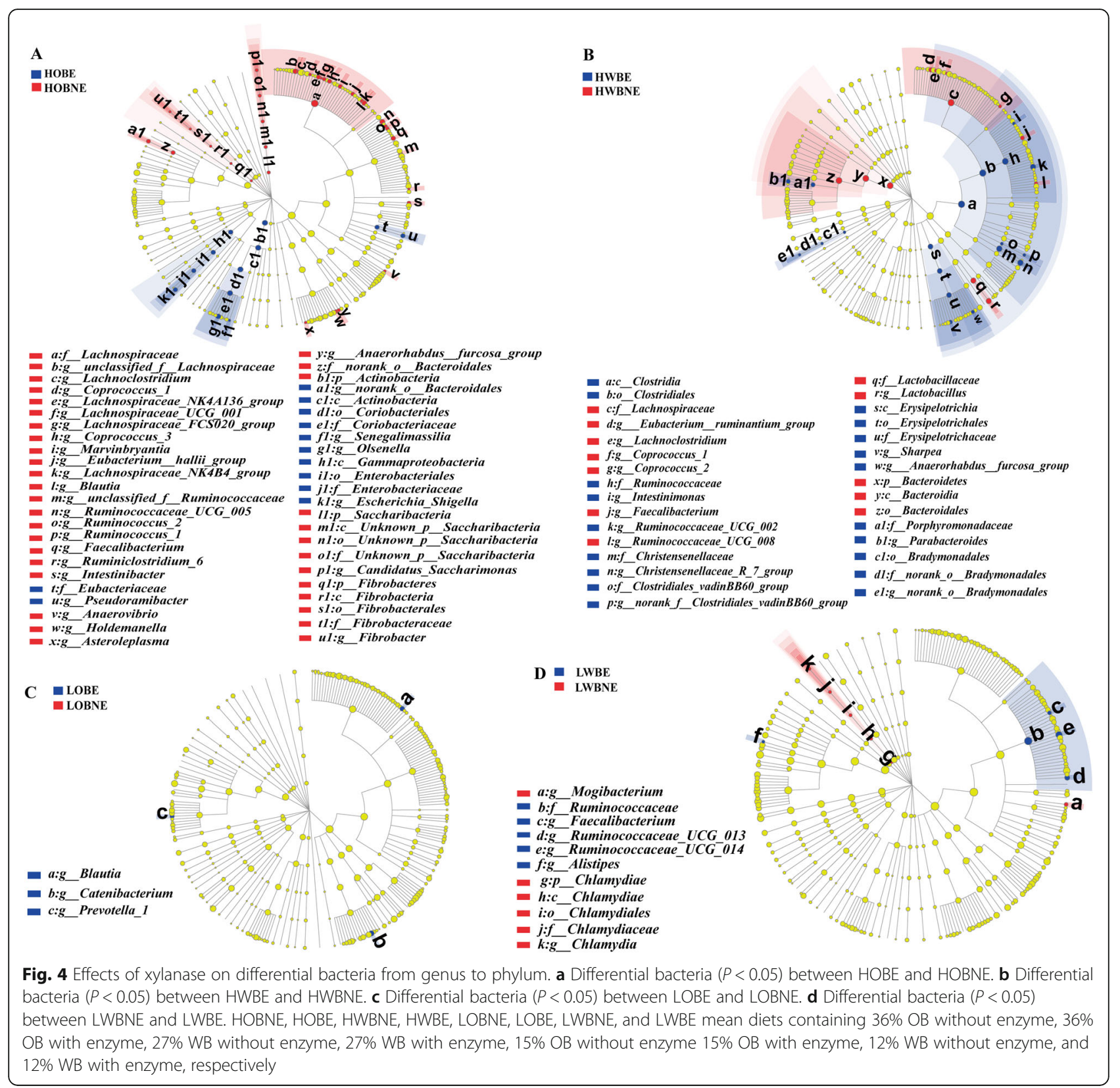

are greater. Similarly, Liu et al. [19] showed that corn branbased diets rich in IDF (mainly insoluble arabinoxylan) increased the population of Bacteroidetes while reducing the abundances of Firmicutes. Bacteroidetes has special polysaccharide utilization loci, which generates numerous carbohydrase enzymes to cleave the linkages that existed in complex polysaccharide structures [29]. Compared with OB diets, WB diets increase the abundance of Succinivibrio which is correlated positively with propionate and butyrate concentrations in feces [30]. The Prevotellaceae are a dominant family within Bacteroidetes phylum and produces numerous enzymes, including xylanases and $\beta$-glucanases, that are reported to be positively associated with arabinoxylan degradation in the gastrointestinal tract of animals [31, 32]. Prevotella has a strong ability to generate acetate [33]. The greater abundances of Prevotella in WB groups compared to OB groups is also reported by Zhang et al. [34] who observes that digestion of NSP and xylose in ileal digesta is correlated positively with abundance of Prevotella. Meanwhile, the concentrations of acetate, propionate and total SCFA are greater in pigs fed 27\% WB diets than those fed 36\% OB diets, which is consistent with the results about fecal bacteria. Our findings support the hypothesis that differences in chemical composition for $\mathrm{OB}$ diets and WB diets affect the abundance of the gut bacteria and concentrations of SCFA, and is ultimately reflected in energy metabolism. 
Inconsistent results regarding the effects of NSPdegrading enzyme on nutrient digestibility based on cereal by-products have been reported widely [28, 35, $36]$. In the current study, the addition of enzyme improves ATTD of nutrients and NE values of diets in pigs fed 27\% WB diets. By contrast, the addition of enzyme to the basal diets or $\mathrm{OB}$ diets does not impact the ATTD of nutrients and NE values of diets. This observation suggests that the effect of enzymes on nutrient digestibility is related to type and concentration of substrates. Hemicellulose in WB consists predominantly of xylose and arabinose residues, and the concentration of arabinoxylan in WB is double than that in $\mathrm{OB}$ [37]. Consequently, diets containing 27\% WB have the greatest arabinoxylan concentration among all diets. According to the theory of enzymatic kinetics, the higher the substrate concentration is, the faster the enzymatic reaction within a certain concentration range [38]. Yin et al. [24] reported that enzyme supplementation had a greater effect on ATTD of nutrients in pigs fed high NSP wheat bran-based diets compared with those fed low NSP wheat or wheat flour diets. Zeng et al. [28] also reported supplementation of carbohydrase increased ATTD of DM (74.5\% vs. $78.0 \%)$ and $\mathrm{CP}(75.4 \%$ vs. $79.7 \%)$ in pigs fed wheat-wheat bran (10\% wheat and 20\% WB) diets, but not in wheat $(10 \%$ wheat) diets. It confirms that effects of enzyme are highly related to type and concentration of the substrates. Additionally, another possible explanation is that $\mathrm{OB}$ contains significant quantities of insoluble arabinoxylans along with soluble $\beta$-glucans [26], so the use of xylanase does not eliminate the anti-nutritional effects of $\beta$-glucans. Soluble $\beta$-glucans increase viscosity of digesta, which, in turn, prevent arabinoxylans to contact with xylanase. The explanation is confirmed by a previous study that reports that xylanase is more efficient in degrading arabinoxylan in wheat than in rye. In addition, Yin et al. [39] reported that $\beta$-glucanase or an enzyme cocktail ( $\beta$-glucanase, xylanase and protease) added to barley diets (higher proportion of $\beta$-glucans) improves ATTD of NDF $(60.9 \%, 68.1 \%, 66.6 \%$ for control diets, $\beta$-glucanase addition diets and cocktai addition diets, respectively) but adding xylanase alone has no effect on the ATTD of NDF although values varied greatly $(60.9 \%$ vs. $67.1 \%)$. It indicates that the effects of enzyme depend on whether the type of enzyme matches the dietary composition. Furthermore, the enzyme addition not only has an impact on digestion of specific NSP but also other nutrients by improving probability for nutrients to contact with endogenous enzymes [14]. In the current study, the enzyme addition improves the NE values only for 27\% WB diets. Because DF provides a negligible net amount of DE to growing pigs [40], the explanation for this result is that the enzyme supplementation improves
ATTD of CP and DM, resulting in more energy sources available to pigs. Exogenous enzymes influenced the intestinal microbiota by enhancing nutrient delivery to the host, providing fermentable oligosaccharides degraded from indigestible polysaccharides, and affecting the fermentation site and viscosity and flow rate of digesta [9, 14]. In general, addition of carbohydrase enzymes influenced more bacterial abundances in pigs fed high-fiber diets compared to pigs fed low-fiber diets. The results were consistent with those of digestibility, SCFA, and energy metabolism in high-fiber diets (mainly $27 \%$ WB diets) and low-fiber diets. Zhao et al. [41] reports that SCFA concentrations in feces are positively correlated with the IDF digestibility in diets. Enzyme addition increases SCFA concentrations in feces when pigs are fed 12\% WB diets, which may be attributed to increased fiber digestibility (57.5\% vs. $60.7 \%$ for NDF and $56.2 \%$ vs. $60.4 \%$ for ADF). However, there is an inconsistent result for effects of enzyme on $27 \%$ WB diets. This maybe because enzyme addition hydrolyzed cell wall components, promoting the digestion of nutrients in the foregut, resulting in a decrease in the substrate available for hindgut fermentation. Enzyme supplementation decreases abundance of Lachnospiraceae, Bacteroidales, and Lactobacillaceae for $27 \%$ WB-fed pigs, which seems to support this explanation. However, comprehensive explanation is not available because SCFA concentrations in feces do not represent the SCFA production in intestinal tract.

\section{Conclusions}

In conclusion, diets supplied by high level of $\mathrm{OB}$ or WB promote the growth of fiber-degrading bacteria. The differences in chemical composition between WB and $\mathrm{OB}$ lead to differences in nutrient digestibility and bacterial communities, which were ultimately reflected in energy metabolism. Enzyme supplementation improves nutrient digestibility as well as NE values for 27\% WB but not for other diets, which indicates that effects of enzyme are determined by type and level of NSP in diets. However, the SCFA production and absorption is not measured in this study, leading to an inability to comprehensively explain the correlation between fatty acids and energy metabolism. Therefore, the effect of dietary structure on digestive properties in different intestinal segments deserves further study.

\section{Supplementary information}

Supplementary information accompanies this paper at https://doi.org/10. 1186/s40104-020-00505-7.

Additional files 1: Table S1. Chemical composition of fibrous ingredients (\%, as-fed basis) ${ }^{1}$. Table S2. Effect of dietary characteristics and xylanase addition on heat production and energy retention of growing pigs ${ }^{1}$. Figure S1. Effects of xylanase on fecal microbial community structure in growing pigs. 


\section{Abbreviations}

AA: Amino acid; ADF: Acid detergent fiber; ATTD: Apparent total tract digestibility; BSNE: The basal diet without xylanase; BW: Body weight; $\mathrm{CH}_{4} \mathrm{E}$ : Energy lost as methane; $\mathrm{CP}$ : Crude protein; DE: Digestible energy; DF: Dietary fiber; DM: Dry matter; EE: Ether extract; FG: Wheat bran diets and oat bran diets without xylanase; FHP: Fasting heat production; GE: Gross energy; HFG: Diet containing 36\% oat bran and diet containing 27\% wheat bran (without enzyme); HP: Heat productionIDFInsoluble dietary fiber: LDA: Linear discriminant analysis effect size; LEfSe: Linear discriminant analysis effect size; LFG: Diets containing $15 \%$ oat bran or $12 \%$ wheat bran (without enzyme); ME: Metabolizable energy; NDF: Neutral detergent fiber; NE: Net energy; NSP: Non-starch polysaccharide; OB: Oat bran; OBNE: Oat bran diets without xylanase; OUT: Operational taxonomic units; OM: Organic matter; RDP: Ribosomal database project; RE: Retained energy; $\mathrm{RE}_{\mathrm{L}}$ : Retained energy as lipids; REp: Retained energy as protein; SCFA: Short-chain fatty acids; SDF: Soluble dietary fiber; TDF: Total dietary fiber; THP: Total heat production; UE: Gross energy of urine; WB: Wheat bran; WBNE: Wheat bran diet without xylanase

\section{Acknowledgements}

Not applicable.

\section{Authors' contributions}

ZQL, SZ and CHL designed the experiment. ZYW and CHL gave advice on the experiment design. ZQL analyzed the study data and prepared the manuscript. The manuscript was edited by LW, CHL, JJW. All the authors have read and approved the final manuscript.

\section{Funding}

This project was financially supported by the National Key Research and Development Program of China (2018YFD0500405), National Natural Science Foundation of China (31630074), National Natural Science Foundation of China (U1604106) and the 111 Project (B16044).

\section{Availability of data and materials}

The data were shown in the main manuscript and supplemental materials.

\section{Ethics approval and consent to participate}

The experimental protocols used in this experiment, including animal care and use, were reviewed and approved by the Animal Care and Use Ethics Committee of China Agricultural University (Beijing, China).

\section{Consent for publication}

Not applicable.

\section{Competing interests}

The authors declare that the research was conducted in the absence of any commercial or financial relationships that could be construed as a potential conflict of interest.

\section{Author details}

${ }^{1}$ State Key Laboratory of Animal Nutrition, College of Animal Science and Technology, China Agricultural University, No. 2 Yuanmingyuan West Road, Beijing 100193, China. 'INRA-Agrocampus, UMR PEGASE1348, Saint-Gilles, 35000 Rennes, France. ${ }^{3}$ College of Bioengineering, Henan University of Technology, Zhengzhou 450001, China. ${ }^{4}$ Jiangsu Youshi Biotechnology Development Co. Ltd., Suqian 223800, Jiangsu, China.

Received: 23 March 2020 Accepted: 14 August 2020 Published online: 08 October 2020

\section{References}

1. Phillips GO, Cui SW. An introduction: evolution and finalisation of the regulatory definition of dietary fibre. Food Hydrocoll. 2011;25:139-43.

2. Morrison DJ, Preston T. Formation of short chain fatty acids by the gut microbiota and their impact on human metabolism. Gut Microbes. 2016;7: 189-200.

3. Iyayi EA, Adeola O. Quantification of short-chain fatty acids and energy production from hindgut fermentation in cannulated pigs fed graded levels of wheat bran. J Anim Sci. 2015;93:4781-7.
4. Besten GD, van Eunen K, Groen AK, Venema K, Reijngoud DJ, Bakker BM The role of short-chain fatty acids in the interplay between diet, gut microbiota, and host energy metabolism. J Lipid Res. 2013;54:2325-40.

5. Sommer F, Ståhlman M, Ilkayeva O, Arnemo JM, Kindberg J, Josefsson J, Newgard CB, Fröbert O, Bäckhed F. The gut microbiota modulates energy metabolism in the hibernating brown bear Ursus arctos. Cell Rep. 2016;14 1655-61.

6. Metzler-Zebeli BU, Zijlstra RT, Mosenthin R, Gänzle MG. Dietary calciumphosphate content and oat $\beta$-glucan influence gastrointestina microbiota, butyrate-producing bacteria and butyrate fermentation in weaned pigs. FEMS Microbiol Ecol. 2011;75:402-13.

7. Bach Knudsen KE, Jensen BB, Hansen I. Digestion of polysaccharides and other major components in the small and large intestine of pigs fed diets consisting of oat fractions rich in $\beta$-D-glucan. Br J Nutr. 1993;70:537-56.

8. Bach Knudsen KE, Canibe N. Breakdown of plant carbohydrates in the digestive tract of pigs fed on wheat- or oat-based rolls. J Sci Food Agric. 2000;80:1253-61.

9. Bedford MR, Cowieson AJ. Exogenous enzymes and their effects on inteatinal microbiology. Anim Feed Sci Technol. 2012;173:76-85.

10. NRC. Nutrient requirements of swine. 10th rev. ed. Natl. Acad. Press, Washington, DC. 2012

11. Lyu ZQ, Li YK, Liu H, Li EK, Li PL, Zhang S, et al. Net energy content of rice bran, defatted rice bran, corn gluten feed, and corn germ meal fed to growing pigs using indirect calorimetry. J Anim Sci. 2018;96:1877-88.

12. Noblet J, Fortune $H$, Shi XS, Dubois S. Prediction of net energy value of feeds for growing pigs. J Anim Sci. 1994;72:344.

13. van Milgen J, Noblet J, Dubois S, Bernier JF. Dynamic aspects of oxygen consumption and carbon dioxide production in swine. Br J Nutr. 1997;78: 397-410.

14. Lærke HN, Arent S, Dalsgaard S, Bach Knudsen KE. Effect of xylanases on ileal viscosity, intestinal fiber modification, and apparent ileal fiber and nutrient digestibility of rye and wheat in growing pigs. J Anim Sci. 2015;93: 4323-35.

15. Hortwitz W, Latimer GW. Official methods of analysis of AOAC international. 18th ed. Rev. 2. ed. AOAC Int., Gaithersburg. 2007.

16. Thiex NJ, Anderson S, Gildemeister B. Crude fat, diethyl ether extraction, in feed, cereal grain, and forage (Randall/Soxtec/submersion method): collaborative study. J AOAC Int. 2003:86:888-98.

17. Van Soest PJ, Robertson JB, Lewis BA. Methods for dietary fiber, neutral detergent fiber, and nonstarch polysaccharides in relation to animal nutrition. J Dairy Sci. 1991;74:3583-97.

18. Prosky L, Asp NG, Schweizer TF, DeVries JW, Furda I. Determination of insoluble and soluble in foods and food-products-collaborative study. J AOAC Int. 1992;75:360-7.

19. Liu P, Zhao JB, Wang W, Guo PT, Lu WQ, Wang CL, et al. Dietary corn bran altered the diversity of microbial communities and cytokine production in weaned pigs. Front Cell Infect Microbiol. 2018:9:2090.

20. Brouwer E. Report of sub-committee on constants and factors. In: Proc. 3rd EAAP Symp. Energy Metab., Troonn, Publ. 11. London, UK: Academic Press; 1965. p. 441-3.

21. van Milgen J, Noblet J, Dubois S. Energetic efficiency of starch, protein and lipid utilization in growing pigs. J Nutr. 2001;131:1309-18.

22. Adeola O. Digestion and balance techniques in pigs. In: Lewis J, Southern LL, editors. Swine nutrition. Washington, DC: CRC Press; 2001. p. 903-16.

23. He BB, Bai $Y$, Jiang LL, Wang W, Li TT, Liu P, et al. Effects of oat bran on nutrient digestibility, intestinal microbiota, and inflammatory responses in the hindgut of growing pigs. Int J Mol Sci. 2018;19:2407.

24. Yin YL, McEvoy JDG, Schulze H, Hennig U, Souffrant WB, McCracken KJ. Apparent digestibility (ileal and overall) of nutrients and endogenous nitrogen losses in growing pigs fed wheat (var. Soissons) or its byproducts without or with xylanase supplementation. Liv Produc Sci. 2000;62:119-32.

25. Choi H, Sung JY, Kim BG. Neutral detergent fiber rather than other dietary fiber types as an independent variable increases the accuracy of prediction equation for digestible energy in feeds for growing pigs. Asian-Australas J Anim Sci. 2020;33:615-22.

26. Bach Knudsen KE. Carbohydrate and lignin contents of plant materials used in animal feeding. Anim Feed Sci Technol. 1997;67:319-38.

27. Johansen HN, Bach Knudsen KE, Wood PJ, Fulcher RG. Physico-chemical properties and the degradation of oat bran polysaccharides in the gut of pigs. J Agric Food Chem. 1997;73:81-92. 
28. Zeng ZK, Li QY, Tian QY, Xu YT, Piao XS. The combination of carbohydrases and phytase to improve nutritional value and non-starch polysaccharides degradation for growing pigs fed diets with or without wheat bran. Anim Feed Sci Technol. 2018:235:138-46.

29. Sonnenburg ED, Zheng HJ, Joglekar P, Higginbottom SK, Firbank SJ, Bolam $\mathrm{DN}$, et al. Specificity of polysaccharide use in intestinal bacteroides species determines diet-induced microbiota alterations. Cell. 2010;141:1241-52.

30. Iqbal MW, Zhang Q, Yang YB, Zou CX, Li LL, Liang X, et al. Ruminal fermentation and microbial community differently influenced by four typical subtropical forages in vitro. Anim Nutr. 2018;4:100-8.

31. Flint HJ, Bayer EA, Rincon MT, Lamed R, White BA. Polysaccharide utilization by gut bacteria: potential for new insights from genomic analysis. Nat Rev Microbiol. 2008;6:121-31.

32. Okeke BC, Lu J. Characterization of a defined cellulolytic and Xylanolytic bacterial consortium for bioprocessing of cellulose and hemicelluloses. Appl Biochem Biotechnol. 2011;163:869-81.

33. Rey FE, Faith JJ, Bain J, Muehlbauer MJ, Stevens RD, Newgard CB, et al. Dissecting the in vivo metabolic potential of two human gut acetogens. J Biol Chem. 2010;285:22082-90.

34. Zhang J, Chen XY, Liu P, Zhao JB, Sun J, Guan WY, et al. Dietary Clostridium butyricum induces a phased shift in fecal microbiota structure and increases the acetic acid-Producin Bacteria in a weaned piglet model. J Agric Food Chem. 2018;66:5157-66.

35. Nørgaard JV, Pedersen TF, Blaabjerg K, Bach Knudsen KE, Lærke HN Xylanase supplementation to rye diets for growing pigs. J Anim Sci. 2016;94: 91-4.

36. Tiwari UP, Chen HY, Kim SW, Jha R. Supplemental effect of xylanase and mannanase on nutrient digestibility and gut health of nursery pigs studied using both in vivo and in vitro models. Anim Feed Sci Technol. 2018;245: 77-90.

37. Yu CY, Zhang SH, Yang Q, Peng Q, Zhu JL, et al. Effect of high fibre diets formulated with different fibrous ingredients on performance, nutrient digestibility and faecal microbiota of weaned piglets. Arch Anim Nutr. 2016; 4:263-77.

38. Truhlar DG. Transition state theory for enzyme kinetics. Arch Biochem Biophys. 2015;582:10-7.

39. Yin YL, Baidoo SK, Jin LZ, Liu YG, Schulze H, Simmins PH. The effect of different carbohydrase and protease supplementation on apparent (ileal and overall) digestibility of nutrients of five hulless barley varieties in young pigs. Livest Prod Sci. 2001;71:109-20.

40. Noblet J, Le Goff G. Effect of dietary fibre on the energy value of feeds for pigs. Anim Feed Sci Technol. 2001;90:35-52.

41. Zhao JB, Bai Y, Zhang G, Liu L, Lai CH. Relationship between dietary fiber fermentation and volatile fatty acids' concentration in growing pigs. Animals. 2020;10:26.

Ready to submit your research? Choose BMC and benefit from:

- fast, convenient online submission

- thorough peer review by experienced researchers in your field

- rapid publication on acceptance

- support for research data, including large and complex data types

- gold Open Access which fosters wider collaboration and increased citations

- maximum visibility for your research: over $100 \mathrm{M}$ website views per year

At $\mathrm{BMC}$, research is always in progress.

Learn more biomedcentral.com/submissions 